\title{
Bridges to excellence quality indicators in inflammatory bowel disease (IBD): differences between IBD and non-IBD gastroenterologists
}

\author{
Mohammad Bilala, Shailendra Singh ${ }^{b}$, Helen Lee ${ }^{b}$, Kiranpreet Khosa ${ }^{b}$, Raman Khehrab ${ }^{b}$ Kofi Clarke, \\ Allegheny General Hospital, Pittsburgh, PA, USA
}

\section{Abstract}

\section{Introduction}

Inflammatory bowel disease (IBD) is the term for a group of chronic complex immune-mediated disorders of

${ }^{a}$ Department of Internal Medicine (Mohammad Bilal, Kiranpreet Khosa, Kofi Clarke); ${ }^{b}$ Division of Gastroenterology, Hepatology and Nutrition (Shailendra Singh, Helen Lee, Kiranpreet Khosa, Raman Khehra, Kofi Clarke), Allegheny General Hospital, Pittsburgh, PA, USA

Conflict of Interest: Kofi Clarke is on the speaker's bureau for AbbVie, Takeda and Janssen. Kofi Clarke has a grant from Allegheny Health Network for the creation of an IBD registry. Mohammad Bilal, Shailendra Singh, Helen Lee, Kiranpreet Khosa and Raman Khehra have no conflicts of interest or financial disclosures to declare

Correspondence to: Mohammad Bilal, MD, 320 East North Ave, Pittsburgh, PA 15212, USA, Tel.: +1 4126603624 ,

Fax: +1 412359 8439, e-mail: billa17@hotmail.com

Received 12 September 2016; accepted 28 November 2016; published online 16 December 2016

DOI: https://doi.org/10.20524/aog.2016.0114 the gastrointestinal tract that includes ulcerative colitis (UC) and Crohn's disease (CD). The aim of treatment is to achieve clinical and endoscopic remission [1,2]. There are several pharmacotherapy options available for the management of IBD, including 5-aminosalicylicates (5-ASA), thiopurines and monoclonal antibodies against tumor necrosis factor [3-5].

With recent advancements in pharmacotherapy for IBD patients, there has been an increased focus on quality indicators (QI) in IBD management. As part of efforts to improve the quality of care delivered to IBD patients, the American Gastroenterology Association (AGA) introduced its first "Bridges to Excellence (BTE)" program in 2011 [6]. The goals of the program included providing quality care to patients, and establishing a tool to measure the delivery of care for patients and serve as a guideline for reimbursements. Since then, there has been a consensus on the importance of QI in the gastroenterology community. The Crohn's and Colitis Foundation of America (CCFA) has also established QI for IBD patients [7].

In recent years, the need for QI in IBD patients has been accepted worldwide $[8,9]$. Although there is a consensus 
regarding the importance of QI in the IBD population, little is known about compliance with these QI amongst gastroenterologists $[7,8,10,11]$. A recent study by Feuerstein et al reported poor compliance with quality metrics in IBD patients: only $6.5 \%$ of patients had all applicable quality metrics documented [12].

We performed a retrospective study to assess the use of BTE QI measures in the care of IBD patients among IBD and nonIBD gastroenterologists at our tertiary care hospital.

\section{Patients and methods}

Patients with a known diagnosis of IBD seen at our tertiary care digestive diseases center between January 2013 and March 2015 were included in the study. Excluded were: patients younger than 18 years; patients lost to follow up; and pregnant patients. Patients were divided into two groups: i) those with care provided by IBD specialists with more than $50 \%$ of their practice dedicated to IBD, who practiced at the IBD Center of Allegheny General Hospital; and ii) those with care provided by non-IBD gastroenterologists.

The study was approved by the institutional review board at Allegheny General Hospital.

The AGA BTE core measures includes: i) documentation of IBD type, anatomic location, and activity; ii) recommendation for corticosteroid-sparing therapy among patients unable to taper off corticosteroids; iii) assessment of bone loss among patients at risk for corticosteroid-related iatrogenic injury; iv) recommendation for influenza immunization; v) recommendation for pneumococcal immunization; vi) screening for latent tuberculosis before initiating antitumor necrosis factor (anti-TNF) therapy; vii) assessment of hepatitis B virus status before initiating anti-TNF therapy; and viii) screening for tobacco use and cessation if relevant [6].

The institutional electronic health record was queried for documentation of baseline patient characteristics (Table 1) and

Table 1 Characteristics of patients cared by IBD versus non-IBD gastroenterologists

\begin{tabular}{|c|c|c|c|}
\hline Characteristic & $\begin{array}{l}\text { IBD physician } \\
n=216\end{array}$ & $\begin{array}{l}\text { Non-IBD physician } \\
\qquad \mathrm{n}=109\end{array}$ & P-value \\
\hline Age, years $($ mean $\pm S D)$ & $43.1 \pm 15.5$ & $52.8 \pm 17.0$ & 0.001 \\
\hline Male sex & $44.9 \%$ & $49.5 \%$ & 0.43 \\
\hline $\begin{array}{l}\text { IBD type: } \\
\text { Crohn's disease } \\
\text { Ulcerative colitis } \\
\text { Indeterminate }\end{array}$ & $\begin{array}{c}59.7 \% \\
38.0 \% \\
2.3 \%\end{array}$ & $\begin{array}{c}47.7 \% \\
49.5 \% \\
2.8 \%\end{array}$ & 0.12 \\
\hline Disease duration, years (mean \pm SD) & $11.2 \pm 8.6$ & $14.0 \pm 12.1$ & 0.02 \\
\hline $\begin{array}{l}\text { Current steroids (excluding new diagnosi } \\
\text { Prednisone } \\
\text { Budesonide }\end{array}$ & $\begin{array}{c}14.8 \% \\
8.3 \%\end{array}$ & $\begin{array}{c}25.0 \% \\
0.0 \%\end{array}$ & 0.01 \\
\hline Immunomodulator use & $35.7 \%$ & $16.5 \%$ & 0.001 \\
\hline Biologic use & $45.8 \%$ & $22.9 \%$ & 0.001 \\
\hline Previous surgery & $37.5 \%$ & $18.4 \%$ & 0.001 \\
\hline $\begin{array}{l}\text { Anatomic location: } \\
\text { Colon } \\
\text { Small bowel } \\
\text { Small bowel+colon } \\
\text { Pan-colitis } \\
\text { Left sided }\end{array}$ & $\begin{array}{l}18.1 \% \\
13.0 \% \\
34.3 \% \\
19.4 \% \\
13.9 \%\end{array}$ & $\begin{array}{c}11.9 \% \\
6.4 \% \\
24.8 \% \\
19.3 \% \\
36.7 \%\end{array}$ & 0.001 \\
\hline $\begin{array}{l}\text { Disease activity: } \\
\text { Mild } \\
\text { Moderate } \\
\text { Severe }\end{array}$ & $\begin{array}{l}37.0 \% \\
36.6 \% \\
26.4 \%\end{array}$ & $\begin{array}{l}75.2 \% \\
11.9 \% \\
12.8 \%\end{array}$ & 0.001 \\
\hline External manifestations & $12.0 \%$ & $11.0 \%$ & 0.78 \\
\hline Steroid-free clinical remission for 1 year & $61.0 \%$ & $67.9 \%$ & 0.49 \\
\hline Current use of narcotic analgesics & $11.6 \%$ & $11.9 \%$ & 0.92 \\
\hline Albumin, $g($ mean \pm SD $)$ & $4.1 \pm 0.5$ & $4.1 \pm 0.5$ & 0.97 \\
\hline Anemia & $31.8 \%$ & $32.3 \%$ & 0.82 \\
\hline Quantitative CRP $($ mean \pm SD) & $2.6 \pm 4.3$ & $4.1 \pm 8.0$ & 0.13 \\
\hline
\end{tabular}

CRP, C-reactive protein; IBD, inflammatory bowel disease; $S D$, standard deviation 
adherence to eight AGA BTE IBD QI (Table 2). Each chart was reviewed for documentation of compliance with the applicable IBD core measures. All records were reviewed for documentation up to 1 year prior to their last documented date of visit. This was done to improve capture and confirm documentation of the IBD core measures. Documentation of testing for latent tuberculosis prior to initiation of anti-TNF therapy was assessed within 6 months, with either a documented tuberculosis skin test or a QuantiFERON gold test. If either of these tests was positive, a chest X-ray was assessed for latent tuberculosis. Bone loss was assessed by reviewing DEXA scan test results.

Table 2 IBD bridges to excellence core measures

IBD bridges to excellence measures

\begin{tabular}{|c|c|}
\hline Measure & Score \\
\hline $\begin{array}{l}\text { Measure } 1 \\
\text { I. IBD type } \\
\text { II. Anatomic location } \\
\text { III. Disease activity } \\
\text { IV. External manifestations }\end{array}$ & 20 \\
\hline $\begin{array}{l}\text { Measure } 2 \\
\quad \text { Corticosteroid-sparing therapy prescribed }\end{array}$ & 20 \\
\hline $\begin{array}{l}\text { Measure } 3 \\
\text { Bone-loss assessment for patients receiving } \\
\text { corticosteroid therapy }\end{array}$ & 15 \\
\hline $\begin{array}{l}\text { Measure } 4 \\
\quad \text { Testing for latent TB before initiating anti-TNF therapy }\end{array}$ & 10 \\
\hline $\begin{array}{l}\text { Measure } 5 \\
\text { Assessment of hepatitis B virus before initiating } \\
\text { anti-TNF therapy }\end{array}$ & 10 \\
\hline $\begin{array}{l}\text { Measure } 6 \\
\quad \text { Influenza immunization }\end{array}$ & 5 \\
\hline $\begin{array}{l}\text { Measure } 7 \\
\quad \text { Pneumococcal immunization }\end{array}$ & 5 \\
\hline $\begin{array}{l}\text { Measure } 8 \\
\text { Tobacco screening and cessation counseling }\end{array}$ & 15 \\
\hline
\end{tabular}

Adherence to quality measures was calculated for each group as the percentage of quality measures completed out of total core measures. Each core measure was given equal weight for the calculation of percentage adherence. We calculated the overall average score out of 100 for each group. Full points were assigned if the core measure was completed and no points were assigned if core measure was incomplete or not documented (Table 2).

\section{Statistical analysis}

The statistical analysis was performed using STATA version 14 (STATA, College Station, TX). Categorical variables were reported as number (percentage). Continuous variables are reported as mean \pm standard deviation. Continuous variables were compared using the two-sample $t$-test and categorical variables using Pearson's $\chi^{2}$. A two-sided P-value of 0.05 was used to determine statistical significance.

\section{Results}

A total of 325 IBD patients who met the inclusion criteria were included in the study. Of these, 216 patients received care from an IBD physician and 109 received care from a non-IBD physician.

Table 1 shows a comparison of the patient characteristics in the 2 groups. Overall, patients managed by IBD physicians were younger $(\mathrm{P}=0.001)$ and had longer-duration $(\mathrm{P}=0.02)$ and more severe disease $(\mathrm{P}=0.001)$ compared to the non-IBD group. There was no significant difference in sex distribution $(\mathrm{P}=0.43)$ or IBD disease location between the two groups $(\mathrm{P}=0.12)$. The use of anti-TNF- $\alpha$ and immunomodulator therapy was higher in the IBD physician group $(\mathrm{P}=0.001)$.

Adherence to BTE quality measures is compared in Table 3. Both IBD and non-IBD physicians were $100 \%$ compliant in assessing the IBD type, anatomic location and disease activity. Use of corticosteroid-sparing therapies was higher among IBD

Table 3 Compliance with BTE quality indicators among IBD and non-IBD gastroenterologists

\begin{tabular}{lccc}
\hline Quality measures & $\begin{array}{c}\text { IBD physicians } \\
\mathrm{n}=216\end{array}$ & $\begin{array}{c}\text { Non-IBD physicians } \\
\mathrm{n}=109\end{array}$ & P-value \\
\hline Corticosteroid-sparing therapies & $43.9 \%$ & $20.3 \%$ & $100 \%$ \\
\hline Type, anatomic location and activity assessed & $100 \%$ & $35.5 \%$ & - \\
Bone loss assessment & $65.7 \%$ & $45.9 \%$ & 0.001 \\
\hline Influenza immunization & $61.4 \%$ & $34.3 \%$ & 0.008 \\
Pneumococcal immunization & $57.7 \%$ & $100 \%$ & 0.001 \\
Testing for latent tuberculosis before initiating anti-TNF therapy & $72.1 \%$ & $95.7 \%$ & 0.004 \\
Assessment of hepatitis B virus before initiating anti-TNF therapy & $79.1 \%$ & $89.0 \%$ & 0.06 \\
Tobacco screening/cessation counseling & $96.8 \%$ & $58.8 \%$ & 0.15 \\
Adherence (percentage of core measures completed) & $71.8 \%$ & 66.3 & 0.001 \\
\hline Average score out of 100 (Based on AGA BTE 100 point score) & 73.9 & 0.001 \\
\hline
\end{tabular}

AGA, American Gastroenterology Association; BTE, bridges to excellence; IBD, inflammatory bowel disease; TNF, tumor necrosis factor 
physicians ( $43.9 \%$ vs. $20.3 \%, \mathrm{P}=0.001$ ). Bone loss assessment and immunizations for both influenza and pneumococcal were performed more by IBD physicians $(\mathrm{P}<0.001)$. NonIBD physicians performed better as regards testing for latent tuberculosis $(\mathrm{P}=0.004)$ and assessment of hepatitis $\mathrm{B}$ virus status before initiating anti-TNF therapy $(\mathrm{P}=0.06)$, compared to IBD physicians.

Overall adherence to the quality measures was higher for IBD physicians than for non-IBD physicians $(71.8 \%$ vs. $58.8 \%, \mathrm{P}=0.001)$. IBD physicians had a higher average score on the AGA BTE 100 point scale (73.9 vs. $66.3, \mathrm{P}=0.001$ ) compared to non-IBD physicians. Both groups scored above the recommended score of 60 .

\section{Discussion}

There are wide variations in the standard of care of IBD patients. This has led to the development of quality metrics for the care of IBD patients. The AGA, CCFA and other societies have identified and developed core metrics in an effort to standardize the quality of care for IBD patients $[8,9,11,13]$. Although there is a consensus amongst various gastroenterology societies concerning the QI, there continues to be a paucity of literature on the actual compliance with these QI measures.

Recent studies have reported poor compliance with IBD QI measures amongst gastroenterologists [12,14,15]. Within gastroenterology, there are additional areas of interest and specialization. This has led to a focus on particular areas of interest amongst gastroenterologists: IBD; pancreatic disorders; motility; liver transplantation; and general hepatology. Gastroenterologists may have difficulty keeping up with all aspects of the constantly changing literature. To our knowledge, no previous study has compared the compliance with IBD BTE QI measures amongst IBD specialist and nonIBD gastroenterologists in the same institution.

Previous reports have shown compliance with tobacco cessation counseling to be the highest, while compliance with pneumococcal immunization was the lowest [12,16]. Our study showed $100 \%$ compliance with documentation of IBD type, anatomic location and activity assessment in both groups. The overall compliance of IBD specialists with QI (calculated using the AGA and Health Care Incentives 100-point scale) was better than that of non-IBD gastroenterologists. IBD specialists performed better in all components of the BTE QI apart from testing for latent tuberculosis and hepatitis B virus prior to the initiation of anti-TNF therapy. This is a surprising finding, since our data also showed that more IBD specialists than non-IBD physicians use anti-TNF therapy. This could perhaps be attributed to the fact that patients with more severe disease were seen by IBD specialists; these patients were likely to have been tested at other centers prior to their referral to our IBD center.

The lowest compliance in our study was seen with use of corticosteroid-sparing therapy in both groups. However IBD physicians performed twice as well as non-IBD physicians.
Previous studies have shown that, despite large initiatives for quality improvement in IBD patients, compliance with QI continues to be low [12,14-16]. It is, however, encouraging that in our study both groups of physicians exceeded the AGA recommended score of 60 . This trend was also reported by Feuerstein et al, who found that specialist IBD physicians demonstrated better compliance with core measures than their counterparts [12]. This raises the important question as to whether patients with IBD would be better served in a specialized IBD clinic, where they would be seen by a physician with a dedicated interest in the IBD population.

There is increased pressure on physicians to stay up to date and provide quality care in an efficient manner, despite the rapidly changing literature across gastroenterology. In the future, compliance with QI measures will have a significant impact on physician reimbursements.

Our study had some limitations in that it was a singlecenter retrospective study. We also did not evaluate the reasons for lack of compliance with QI in either group. However, the sample size was large and we were able to compare the practices

\section{Summary Box}

\section{What is already known:}

- The American Gastroenterology Association introduced its first "Bridges to Excellence (BTE)" program in 2011

- Since then, there has been a consensus on the importance of adhering to quality indicators (QI) in the care of inflammatory bowel disease (IBD) patients

- The Crohn's and Colitis Foundation of American has also established QI indicators for the care of IBD patients

- Despite a growing consensus on these core measures, there is a paucity of data about compliance with these QI amongst gastroenterologists

\section{What the new findings are:}

- Gastroenterologists who have expertise in IBD and focus on the care of IBD patients perform better in terms of compliance to BTE core measures

- IBD patients may receive a better quality of care when managed by IBD gastroenterologists; a longer follow up is needed, with outcome measures that include clinical and endoscopic remission

- Our study raises the important question as to whether patients with severe IBD would be better served by care in a specialized IBD clinic, where they would be seen by a physician with dedicated interest in the IBD population 
of non-IBD gastroenterologists with those of IBD specialists at the same institution.

Proposed next steps include: i) feedback information provided to our gastroenterologists on their performance; ii) re-enforcement/education of our general gastroenterologists and IBD gastroenterologists on BTE measures in IBD; iii) evaluation of the impact of compliance with BTE QI indicators on other clinical parameters, such as fracture rates, pneumonia, and influenza infection, in our IBD patients; and iv) development of an IBD "core measures" checklist in the electronic medical record.

In conclusion, our study suggests that IBD patients may receive a better quality of care when managed by IBD specialists.

\section{References}

1. Kornbluth A, Sachar DB; Practice Parameters Committee of the American College of Gastroenterology. Ulcerative colitis practice guidelines in adults: American College Of Gastroenterology, Practice Parameters Committee. Am J Gastroenterol 2010; 105:501-523.

2. Lichtenstein GR, Hanauer SB, Sandborn WJ; Practice Parameters Committee of American College of Gastroenterology. Management of Crohn's disease in adults. Am J Gastroenterol 2009;104:465-483.

3. Mowat C, Cole A, Windsor A, et al; IBD Section of the British Society of Gastroenterology. Guidelines for the management of inflammatory bowel disease in adults. Gut 2011;60:571-607.

4. Travis SP, Stange EF, Lémann M, et al; European Crohn's and Colitis Organisation (ECCO). European evidence-based Consensus on the management of ulcerative colitis: Current management. J Crohns Colitis 2008;2:24-62.

5. Van Assche G, Dignass A, Panes J, et al; European Crohn's and Colitis Organisation (ECCO). The second European evidence- based Consensus on the diagnosis and management of Crohn's disease: Definitions and diagnosis. J Crohns Colitis 2010;4:7-27.

6. American Gastroenterological Association. Adult inflammatory bowel disease physician performance measures set. 2011: www. gastro.org/practice/quality-initiatives/IBD_Measures.pdf. Accessed December 2, 2016.

7. Melmed GY, Siegel CA, Spiegel BM, et al. Quality indicators for inflammatory bowel disease: development of process and outcome measures. Inflamm Bowel Dis 2013;19:662-668.

8. Nguyen GC, Devlin SM, Afif W, et al. Defining quality indicators for best-practice management of inflammatory bowel disease in Canada. Can J Gastroenterol Hepatol 2014;28:275-285.

9. Seo GS. [Quality of care in inflammatory bowel disease]. Korean J Gastroenterol 2015;65:139-144.

10. Ahmed S, Siegel CA, Melmed GY. Implementing quality measures for inflammatory bowel disease. Curr Gastroenterol Rep 2015;17:14.

11. Melmed GY, Siegel CA. Quality improvement in inflammatory bowel disease. Gastroenterol Hepatol (N Y) 2013;9:286-292.

12. Feuerstein JD, Lewandowski JJ, Martinez-Vazquez M, Leffler DA, Cheifetz AS. Documented compliance with inflammatory bowel disease quality measures is poor. Dig Dis Sci 2015;60:339-344.

13. IBD Care Recognition | Health Care Incentives Improvement Institute, Inc. (HCI3). 2016; Available from: http://www.hci3.org/ programs-efforts/bridges-to-excellence/recognition_programs/ ibd_care_recognition. Accessed December 2, 2016.

14. Lee AJ, Kraemer DF, Smotherman C, Eid E. Providing our fellows in training with education on inflammatory bowel disease health maintenance to improve the quality of care in our health care system. Inflamm Bowel Dis 2016;22:187-193.

15. Lee NS, Pola S, Groessl EJ, Rivera-Nieves J, Ho SB. Opportunities for improvement in the care of patients hospitalized for inflammatory bowel disease-related colitis. Dig Dis Sci 2016;61:1003-1012.

16. Greene L, Moreo K. Quality improvement education to improve performance on ulcerative colitis quality measures and care processes aligned with National Quality Strategy priorities. BMJ Qual Improv Rep 2015;4:pii: u208829.w3554. 